\title{
Respiratory Muscle Strength During and After Hospitalization for COPD Exacerbation
}

\author{
Rafael Mesquita PT MSc, Leila Donária PT, Isabel CH Genz PT, \\ Fabio Pitta PT PhD, and Vanessa S Probst PT PhD
}

\begin{abstract}
BACKGROUND: A more profound investigation of respiratory muscle strength during COPD exacerbation was needed, so we investigated respiratory muscle strength and related factors in patients with COPD during and after hospitalization for COPD exacerbation. METHODS: In 19 subjects hospitalized for COPD exacerbation $(12$ males, mean age $67 \pm 11 \mathrm{y}$, median percent-ofpredicted $\mathrm{FEV}_{1} 26 \%$ [IQR 19-32\%]) we measured lung function and respiratory and quadriceps muscle strength at admission (day 1), at discharge, and 1 month after discharge. RESULTS: At admission, $68 \%$ of the subjects had inspiratory muscle dysfunction (maximum inspiratory pressure $<70 \%$ of predicted). Inspiratory muscle strength increased between day $1\left(56 \mathrm{~cm} \mathrm{H}_{2} \mathrm{O}\right.$ [IQR 45-64 $\mathrm{cm} \mathrm{H} \mathrm{H}_{2} \mathrm{O}$ ]) and 1 month after discharge $\left(65 \mathrm{~cm} \mathrm{H}_{2} \mathrm{O}\right.$ [IQR 51-74 $\mathrm{cm} \mathrm{H}_{2} \mathrm{O}$ ], $\left.P=.007\right)$. Expiratory muscle strength increased between day $1\left(99 \mathrm{~cm} \mathrm{H}_{2} \mathrm{O}\left[65-117 \mathrm{~cm} \mathrm{H}_{2} \mathrm{O}\right]\right)$ and discharge $\left(109 \mathrm{~cm} \mathrm{H}_{2} \mathrm{O}\right.$ [77-136 $\mathrm{cm} \mathrm{H}_{2} \mathrm{O}$ ], $\left.P=.005\right)$, and between day 1 and 1 month after discharge $\left(114 \mathrm{~cm} \mathrm{H}_{2} \mathrm{O}\right.$ [90-139 $\left.\left.\mathrm{cm} \mathrm{H}_{2} \mathrm{O}\right], P=.001\right)$. Inspiratory capacity increased between discharge $(1.59 \pm 0.44 \mathrm{~L})$ and 1 month after discharge $(1.99 \pm 0.54 \mathrm{~L}, P=.02)$. There was no significant change in other lung function variables or quadriceps strength. At admission the inspiratory muscle dysfunction and reduction in inspiratory capacity $(<80 \%$ of predicted) correlated linearly (phi coefficient $0.62, P=.03$ ), whereas the expiratory muscle strength correlated inversely with $F E V_{1}$ (Spearman rho $-0.61, P=.005$ ) and inspiratory capacity (Spearman rho $-0.54, P=.02$ ). CONCLUSIONS: There was a high prevalence of inspiratory muscle dysfunction in patients hospitalized for COPD exacerbation. Inspiratory and expiratory muscle strength increased markedly during and after hospitalization. The degree of air-flow obstruction and hyperinflation were related to inspiratory and expiratory muscle strength. Key words: COPD; exacerbation; hospitalization; respiratory muscles; respiratory muscle strength. [Respir Care 2013;58(12):2142-2149. (C) 2013 Daedalus Enterprises]
\end{abstract}

\section{Introduction}

Exacerbation of COPD is well known as harmful and common in the natural course of the disease. The Global Initiative for Chronic Obstructive Lung Disease (GOLD)

The authors are affiliated with Laboratório de Pesquisa em Fisioterapia Pulmonar, Departamento de Fisioterapia, Universidade Estadual de Londrina, Londrina, Paraná, Brazil. Mr Mesquita, Dr Pitta, and Dr Probst are also affiliated with Programa de Mestrado em Ciências da Reabilitação, Universidade Estadual de Londrina, Universidade Norte do Paraná, Londrina, Paraná, Brazil. Mr Mesquita and Dr Probst are also affiliated with Centro de Pesquisa em Ciências da Saúde, Universidade Norte do Paraná, Londrina, Paraná, Brazil.

Mr Mesquita presented a version of this paper at the Annual Congress of the European Respiratory Society, held September 24-28, 2011, in Amsterdam, Netherlands. defines COPD exacerbation as an acute event characterized by a worsening of respiratory symptoms beyond nor-

\footnotetext{
This research was partly supported by grant $474513 / 2009-2$ from Conselho Nacional de Desenvolvimento Científico e Tecnológico, Brazil. Mr Mesquita was partly supported by Coordenação de Aperfeiçoamento de Pessoal de Nível Superior/Programa de Suporte à Pós-Graduação de Instituições de Ensino Particulares, Brazil, Dr Pitta was partly supported by Conselho Nacional de Desenvolvimento Científico e Tecnológico, Brazil. Dr Probst was partly supported by Fundação Nacional de Desenvolvimento do Ensino Superior Particular. The authors have disclosed no conflicts of interest.

Correspondence: Fabio Pitta PhD, Departamento de Fisioterapia, Centro de Ciências da Saúde, Hospital Universitário de Londrina, Avenida Robert Koch 60, Vila Operária, 86038-350, Londrina, Paraná, Brazil. E-mail: fabiopitta@uol.com.br.
}

DOI: $10.4187 /$ respcare. 02393 
mal day-to-day variations and that requires a change in medication. ${ }^{1}$

Among the main consequences of COPD exacerbation presented in the literature, the following can be highlighted due to their direct impact on the patient's health: increase in mortality, ${ }^{2}$ impairment in health-related quality of life, ${ }^{3}$ faster decline in lung function, ${ }^{4}$ marked reduction in physical activity level, ${ }^{5}$ and worsening of peripheral muscle weakness. ${ }^{6}$

Despite the key importance of the respiratory muscles in COPD, only a few studies have focused on the relationship between the respiratory muscles and the exacerbation process. Two recent cross-sectional studies found that respiratory muscle dysfunction is associated with an increased risk of hospital admission for exacerbation.7,8 Two other prospective studies identified inspiratory muscle overload as a risk factor for hospitalization for exacerbation. ${ }^{9,10}$ Surprisingly, the respiratory muscle function during and after COPD exacerbation seems to have been poorly investigated. We identified only 3 studies that prospectively assessed respiratory muscle strength during and after hospitalization for COPD exacerbation.5,11,12 González et al ${ }^{12}$ and Martínez-Llorens et $\mathrm{al}^{11}$ found an increase in inspiratory muscle strength between admission and discharge, whereas Pitta et $\mathrm{al}^{5}$ found no statistically significant change in inspiratory muscle strength during or after hospitalization. Expiratory muscle strength decreased during hospitalization in the study by Martínez-Llorens et al, ${ }^{11}$ but remained unaltered in the study by Pitta et al. ${ }^{5}$ Decreased respiratory muscle strength is an important sign, because it is associated with worse dyspnea and exercise intolerance, ${ }^{13}$ which are associated with disease severity.

The evolution of respiratory muscle strength during COPD exacerbation needs to be better understood, so we measured inspiratory and expiratory respiratory muscle strength and related factors in patients hospitalized for COPD exacerbation.

\section{Methods}

This study was approved by the ethics committee of Universidade Estadual de Londrina, Londrina, Paraná, Brazil, and all subjects gave written informed consent.

\section{Study Design}

This observational study was carried out from January 2010 to February 2012. We recruited patients hospitalized for COPD exacerbation at our university hospital, Universidade Estadual de Londrina, Londrina, Paraná, Brazil. We measured respiratory and quadriceps muscle strength and lung function in the first 24 hours of hospitalization (day 1), and again at discharge and 1 month after discharge. At 1 month after discharge the subjects returned to the hos-

\section{QUICK LOOK}

\section{Current knowledge}

COPD exacerbation is defined as a worsening of respiratory symptoms beyond normal day-to-day variations and that requires a change in medication. Among the main consequences of COPD exacerbation are an increase in mortality, impairment in health-related quality of life, faster decline in lung function, marked reduction in physical activity, and worsening of peripheral muscle weakness.

\section{What this paper contributes to our knowledge}

Inspiratory muscle dysfunction at hospital admission is common during COPD exacerbation. Inspiratory and expiratory muscle strength increased markedly during and after hospitalization. The degree of airflow obstruction and hyperinflation at hospital admission were related to both inspiratory and expiratory muscle strength.

pital to be reassessed. We assessed arterial blood gases and symptoms, and made the combined COPD assessment only on day 1 .

\section{Subjects}

The inclusion criteria were: COPD diagnosis per the GOLD criteria ${ }^{1}$ (post-bronchodilator $\mathrm{FEV}_{1} / \mathrm{FVC}<0.70$ ); hospital admission due to COPD exacerbation (ie, severe exacerbation according to the definition of RodriguezRoisin $\left.{ }^{14}\right)$; spontaneous breathing on hospital admission (ie, not on mechanical ventilation); no important comorbidities (eg, neuromuscular, cerebrovascular, or severe cardiac disease) that could impair performance in study tests; no recent hospitalization due to COPD exacerbation; and no participation in any exercise training in the previous 6 months. The decision to admit a patient to the hospital was made by the attending physician, who was not involved in the study. The exclusion criteria were: death, withdrew consent, or missed assessment on more than 1 assessment day (ie, discharge and 1 month after discharge).

\section{Assessments}

Sex, age, anthropometric variables (weight, height, and body mass index), and clinical variables (number of exacerbations in the previous year, and previous corticosteroids use) were collected at study inclusion. Data concerning corticosteroid use and physiotherapy treatment 
during the hospitalization were retrieved retrospectively from the subject's medical file after discharge.

Respiratory muscle strength, the primary outcome, was measured as maximum inspiratory pressure $\left(\mathrm{P}_{\mathrm{Imax}}\right)$ and maximum expiratory pressure $\left(\mathrm{P}_{\text {Emax }}\right)$, using a digital manovacuometer (MVD 300, GlobalMed, Porto Alegre, Brazil) and a plastic tube mouthpiece, with a small leak, to prevent glottic closure and to reduce the use of buccal muscles. ${ }^{15}$ We used the Black and Hyatt ${ }^{16}$ protocol, in which the subject is assessed in the seated position, wears a nose clip, the $\mathrm{P}_{\mathrm{Imax}}$ maneuver is begun near residual volume, and the $\mathrm{P}_{\text {Emax }}$ maneuver is begun near total lung capacity. The $\mathrm{P}_{\text {Imax }}$ and $\mathrm{P}_{\text {Emax }}$ maneuvers were maintained for at least 2 seconds, and the peak value was recorded. Although the $\mathrm{P}_{\text {Imax }}$ values are negative, they are presented as positive values, to avoid misinterpretation of the changes in $\mathrm{P}_{\text {Imax }}$. The best of 3 acceptable and reproducible consecutive maneuvers was analyzed. The criteria for acceptability were adequate effort and duration, no postural compensation, and no cough or perioral air leak during the maneuver. The criterion for reproducibility was a difference $\leq 10 \%$ of the highest value between the 2 highest values. Reference values are also used to express the results. ${ }^{17}$

Quadriceps muscle strength was measured as quadriceps peak torque during an isometric contraction of the quadriceps of the dominant side, and at $60^{\circ}$ of knee flexion, ${ }^{18}$ with a dynamometer (microFET2, Hoggan Health, Salt Lake City, Utah) anchored to fixed multi-gym equipment; this adaptation was previously validated. ${ }^{19}$ The best of 3 acceptable and reproducible maneuvers was considered for analysis. Quadriceps peak torque was calculated in joules, Newtons per kilogram, and percent-ofpredicted. ${ }^{20}$ Lung function was measured with spirometry (Spirobank G, MIR Medical International Research, Rome, Italy), with the slow and forced vital capacities after bronchodilation, according to international recommendations ${ }^{21}$ and compared to national reference values. ${ }^{22,23}$ All the tests were performed by a trained physiotherapist.

Arterial blood gases $\left(\mathrm{P}_{\mathrm{aO}_{2}}\right.$ and $\left.\mathrm{P}_{\mathrm{aCO}}\right)$ were measured at admission by the hospital staff. Also at admission, the combined COPD assessment ${ }^{1}$ was performed to get a multidimensional estimate of disease severity. This assessment includes air-flow limitation, exacerbation frequency, and symptoms (assessed with the Medical Research Council scale ${ }^{24}$ ), and classifies patients into 4 groups: low risk and less symptoms; low risk and more symptoms; high risk and less symptoms; and high risk and more symptoms.

\section{Statistical Analyses}

The study by González et al ${ }^{12}$ was used for sample size calculation. Considering the pooled mean $\pm \mathrm{SD} \mathrm{P}_{\mathrm{Imax}}$ difference of $15 \pm 21 \mathrm{~cm} \mathrm{H}_{2} \mathrm{O}$ between hospital admission and discharge, an alpha value of .05 , and a power of $80 \%$, the present study needed a sample size of 17 subjects (using the paired $t$ test). Adding a drop-out rate of 25\%, based on a study with a similar design, ${ }^{5}$ the required sample size increased to 21 subjects.

Categorical variables are described as absolute and/or relative frequencies. Continuous variables were tested for normality with the Shapiro-Wilk test and are presented as mean \pm SD if normally distributed, or median (IQR) if non-normally distributed. The multiple imputation method was used to impute the missing values, which were considered missing completely at random according to Little's missing-completely-at-random test. Only the results with imputed data are presented, unless a difference between these and the results from complete-case analysis was verified.

The chi-square test was used to compare categorical data. Repeated-measures analysis of variance or the Friedman test was used to compare the 3 days of assessment, with the Tukey or Dunn test as the post hoc test, respectively. The changes in the respiratory pressures were compared with the paired $t$ test or Wilcoxon test, and the comparison of the $\mathrm{P}_{\text {Imax }}$ and $\mathrm{P}_{\mathrm{Emax}}$ changes was with the unpaired $t$ test or the Mann-Whitney test. We used the Spearman or phi coefficient to analyze correlations. $P<.05$ was considered a significant difference. The analyses were performed with statistics software (SPSS 17.0, SPSS, Chicago, Illinois, or Prism 5, GraphPad Software, La Jolla, California).

\section{Results}

We included 21 subjects with COPD exacerbation. During the study 2 subjects died from respiratory complications of COPD (one during hospitalization, and the other soon before the assessment 1 month after discharge) and 2 did not attend the last assessment. The 2 subjects who died were excluded, and the 2 who did not attend the follow-up were handled with the multiple imputation method. One subject was hospitalized again after discharge but before the 1 month after discharge assessment. However, a sensitivity analysis revealed that this subject did not bias the results. Subjects who dropped out and the remaining subjects had similar age, anthropometry, and lung function. On the contrary, the subjects who died were older, had lower body mass index, and had more exacerbations in the past year.

\section{Clinical Information Before and During Hospitalization}

Table 1 describes the clinical characteristics of the 19 subjects on the first day of assessment (day 1). The majority of subjects were classified as GOLD stage 4 and 


\section{Respiratory Muscle Strength During and After Hospitalization for COPD Exacerbation}

Table 1. Clinical Characteristics in the First 24 Hours of Hospitalization for COPD Exacerbation

\begin{tabular}{|c|c|}
\hline Male/female & $12 / 7$ \\
\hline Age, mean $\pm \mathrm{SD}$ y & $67 \pm 11$ \\
\hline Body mass index, median (IQR) $\mathrm{kg} / \mathrm{m}^{2}$ & $23(19-27)$ \\
\hline $\mathrm{FEV}_{1}$, median (IQR) $\%$ of predicted & $26(19-32)$ \\
\hline $\mathrm{FEV}_{1} / \mathrm{FVC}$, mean $\pm \mathrm{SD} \%$ & $38 \pm 12$ \\
\hline \multicolumn{2}{|l|}{ GOLD stage } \\
\hline 2 & 1 \\
\hline 3 & 6 \\
\hline 4 & 12 \\
\hline \multicolumn{2}{|l|}{ Exacerbations in the past year, no. (\%) } \\
\hline $0-1$ & $15(79)$ \\
\hline$\geq 2$ & $4(21)$ \\
\hline $\begin{array}{l}\text { Symptoms (Medical Research Council } \\
\text { scale)*, mean } \pm \text { SD }\end{array}$ & $3 \pm 1$ \\
\hline \multicolumn{2}{|l|}{ Combined COPD assessment category, \%* } \\
\hline Low risk and less symptoms & 0 \\
\hline Low risk and more symptoms & 0 \\
\hline High risk and less symptoms & 25 \\
\hline High risk and more symptoms & 75 \\
\hline \multicolumn{2}{|l|}{ Previous corticosteroid use, no. (\%) } \\
\hline Inhaled corticosteroids $\dagger$ & $9(47)$ \\
\hline Oral corticosteroids $\$$ & $3(16)$ \\
\hline $\mathrm{P}_{\mathrm{aO}}$, mean $\pm \mathrm{SD} \mathrm{mm} \mathrm{Hg}$ & $61 \pm 14$ \\
\hline $\mathrm{P}_{\mathrm{aCO}_{2}}$, median (IQR) $\mathrm{mm} \mathrm{Hg}$ & $39(31-43)$ \\
\hline \multicolumn{2}{|c|}{$\begin{array}{l}\text { * Data available for only } 8 \text { subjects, who did not differ from the remainder of subjects in age, } \\
\text { anthropometry, or lung function. } \\
\dagger \text { For a mean period of } 24 \text { months. } \\
¥ 20 \mathrm{mg} / \mathrm{d} \text { prednisone or prednisolone for a mean } 26 \text { months } \\
\text { GOLD = Global Initiative for Chronic Obstructive Lung Disease }\end{array}$} \\
\hline
\end{tabular}

belonged to the high-risk-and-more-symptoms group in the combined COPD assessment. During hospitalization, 16 subjects $(84 \%)$ received systemic corticosteroids (hydrocortisone, prednisone, prednisolone, or methylprednisolone) and $3(16 \%)$ did not receive systemic corticosteroids, 18 subjects $(95 \%)$ received bronchodilators (combination of fenoterol and ipratropium, terbutaline, or tiotropium), and 9 subjects (47\%) received respiratory physiotherapy. The physiotherapy techniques were mainly calisthenics plus breathing exercises or bronchopulmonary hygiene techniques, with no endurance, strength, or respiratory muscle training. The median hospitalization period was 4 (IQR 3-5) days.

\section{Respiratory Muscle Strength During and After Hospitalization}

Figure 1 shows the $\mathrm{P}_{\text {Imax }}$ values during and after hospitalization. In comparison to day $1\left(56 \mathrm{~cm} \mathrm{H}_{2} \mathrm{O}\right.$ [4564] $\mathrm{cm} \mathrm{H}_{2} \mathrm{O}$ ), $\mathrm{P}_{\text {Imax }}$ had not changed significantly at discharge $\left(62 \mathrm{~cm} \mathrm{H}_{2} \mathrm{O}\right.$ [45-69 $\mathrm{cm} \mathrm{H}_{2} \mathrm{O}$ ]), but had increased at 1 month after discharge $\left(65 \mathrm{~cm} \mathrm{H}_{2} \mathrm{O}\right.$ [51-74 $\mathrm{cm} \mathrm{H}_{2} \mathrm{O}$,
$P=.007$ ). $\mathrm{P}_{\text {Emax }}$ showed a similar pattern (see Fig. 1). However, the post hoc test revealed that, in comparison to day 1 (99 $\mathrm{cm} \mathrm{H}_{2} \mathrm{O}$ [65-117 $\left.\mathrm{cm} \mathrm{H}_{2} \mathrm{O}\right]$ ), $\mathrm{P}_{\mathrm{Emax}}$ had increased at discharge $\left(109 \mathrm{~cm} \mathrm{H}_{2} \mathrm{O}\right.$ [77-136 $\left.\left.\mathrm{cm} \mathrm{H}_{2} \mathrm{O}\right], P=.005\right)$ and also at 1 month after discharge $\left(114 \mathrm{~cm} \mathrm{H}_{2} \mathrm{O}\right.$ [90$139 \mathrm{~cm} \mathrm{H}_{2} \mathrm{O}$ ], $P=.001$ ).

There was no significant difference in the change in $\mathrm{P}_{\text {Imax }}$ or $\mathrm{P}_{\mathrm{Emax}}$ (ie, the relative change normalized to the values obtained at day 1) between day 1 and discharge, compared to the difference between day 1 and 1 month after discharge (Fig. 2). The improvement in $\mathrm{P}_{\mathrm{Imax}}$ and $\mathrm{P}_{\mathrm{Emax}}$ from day 1 to discharge accounted for $68 \%$ and $61 \%$, respectively, of the improvement from day 1 to 1 month after discharge. $\mathrm{P}_{\text {Emax }}$ was higher than $\mathrm{P}_{\text {Imax }}$ in the comparison of both the changes from day 1 to discharge $(14 \pm 22 \%$ vs $13 \pm 20 \%$, respectively, $P=.001)$, and from day 1 to 1 month after discharge $(23 \pm 31 \%$ vs $19 \pm 22 \%$, respectively, $P=.003$ ) (see Fig. 2).

At day 1 the $\mathrm{P}_{\text {Imax }}$ correlated significantly with the $\mathrm{P}_{\mathrm{Emax}}$ (Spearman rho $0.49, P=.04$ ) and with the quadriceps peak torque (Spearman rho 0.57, $P=.01$ ), and $\mathrm{P}_{\mathrm{Emax}}$ correlated inversely with percent-of-predicted $\mathrm{FEV}_{1}$ (Spearman rho $-0.61, P=.005$ ) and percent-of-predicted inspiratory capacity (Spearman rho $-0.54, P=.02$ ). On day 1 the proportion of subjects with reduced inspiratory capacity $\left(<80 \%\right.$ of predicted $\left.{ }^{25}\right)$ was the same as the percentage with inspiratory muscle dysfunction (suggested by Vilaró et $\mathrm{al}^{7}$, as $\mathrm{P}_{\text {Imax }}<70 \%$ of predicted), which is 13 subjects $(68 \%)$. Indeed, the inspiratory capacity of patients with inspiratory muscle dysfunction was lower than that of patients without inspiratory muscle dysfunction (62\% of predicted [53-72\% of predicted] vs $93 \%$ of predicted [71$139 \%$ of predicted], respectively, $P=.02$ ), and the classifications of reduced inspiratory capacity and inspiratory muscle dysfunction were associated (phi coefficient 0.62 , $P=.03$ ). The change in $\mathrm{P}_{\text {Imax }}$ between day 1 and 1 month after discharge linearly correlated with those changes in $\mathrm{P}_{\text {Emax }}$ (Spearman rho 0.58, $P=.01$ ), whereas the latter inversely correlated with $\mathrm{P}_{\mathrm{Emax}}$ on day 1 (Spearman rho $-0.52, P=.02)$.

\section{Lung Function and Peripheral Muscle Strength During and After Hospitalization}

The behavior of lung function and peripheral muscle strength during and after hospitalization is shown in Table 2. There was no significant difference in $\mathrm{FEV}_{1}$ or FVC between the 3 assessment days. The inspiratory capacity (in liters) significantly increased between discharge and 1 month after discharge $(P=.02)$. There was no significant change in quadriceps peak torque between the 3 assessment days. During all the assessments no adverse effects were observed. 


\section{Respiratory Muscle Strength During and After Hospitalization for COPD Exacerbation}
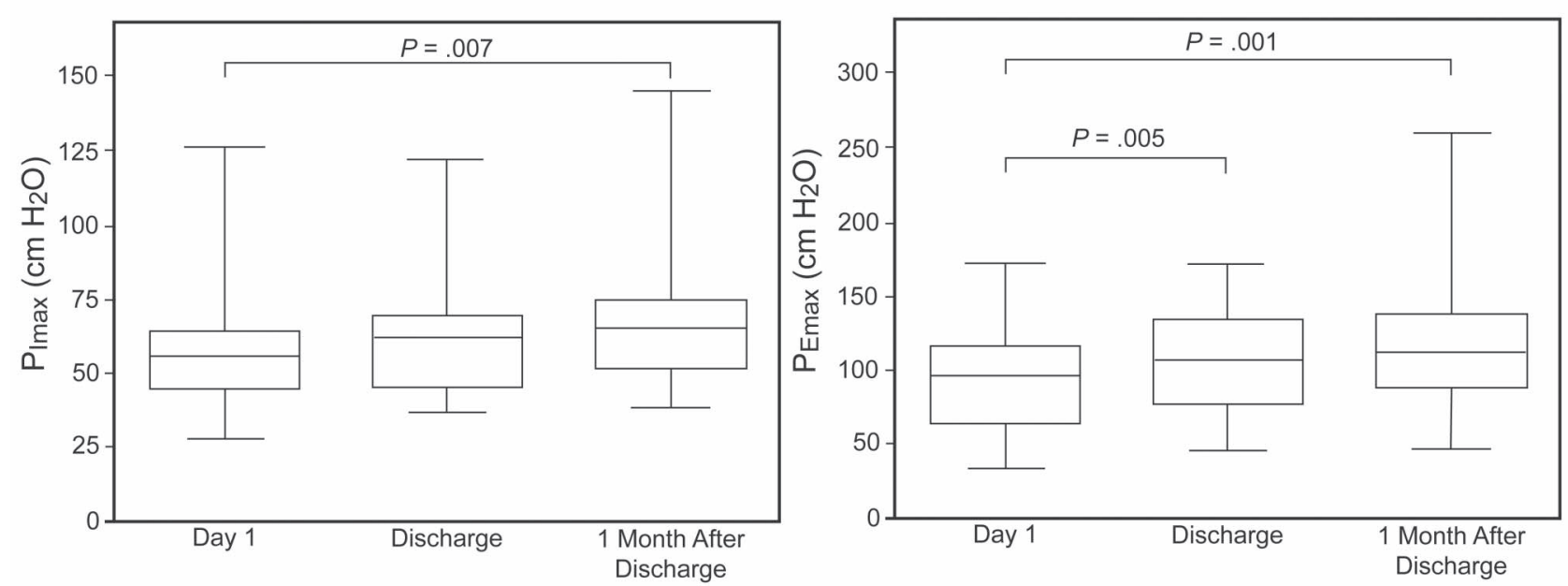

Fig. 1. Maximum inspiratory pressure $\left(P_{\operatorname{Imax}}\right)$ and maximum expiratory pressure $\left(P_{\text {Emax }}\right)$ at admission (day 1$)$, at discharge, and 1 month after discharge, in subjects hospitalized for COPD exacerbation. In each data bar, the horizontal line represents the median, the top and bottom of the bar represent the interquartile range, and the whisker bars represent the range. Friedman test $P$ all $<.03$.

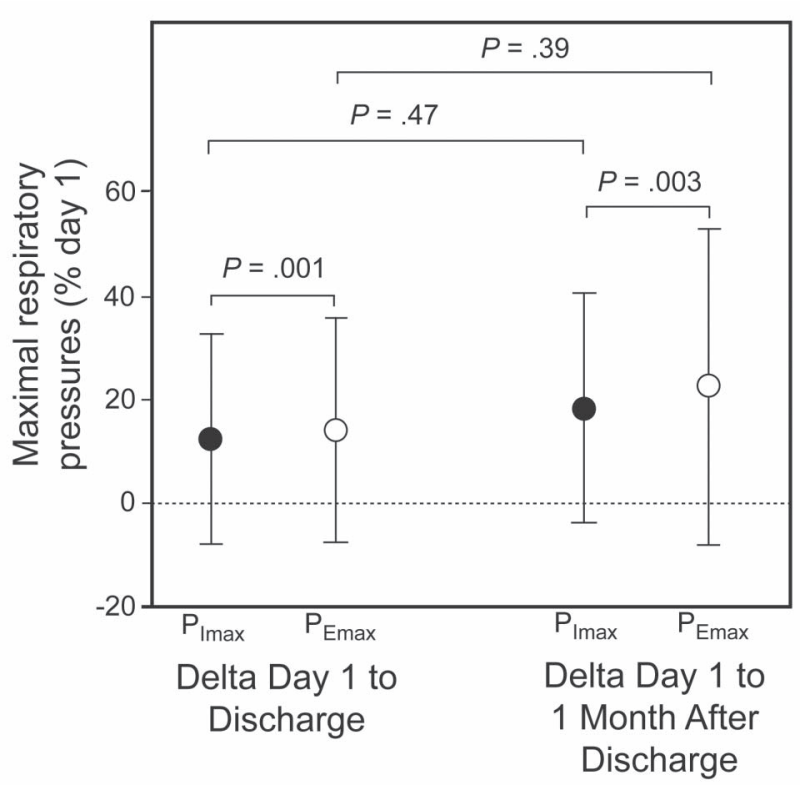

Fig. 2. Mean $\pm S D$ difference in maximum inspiratory pressure $\left(P_{\text {Imax }}\right)$ and maximum expiratory pressure $\left(P_{E \max }\right)$ at day 1 versus at discharge, and at day 1 versus 1 month after discharge.

\section{Discussion}

This study clearly showed that the inspiratory muscle strength is reduced at the onset of a hospitalization for COPD exacerbation, but increases markedly by 1 month after discharge. The expiratory muscle strength presents a similar pattern; it had increased at discharge and at 1 month after discharge. Lung function at hospital admission was related to both inspiratory and expiratory muscle strength.

Two of the 3 studies that have prospectively evaluated inspiratory muscle strength during and/or after hospital- ization found that inspiratory muscle strength increased from admission to discharge, ${ }^{11,12}$ while the other study found a trend of improvement from discharge to 1 month after. ${ }^{5}$ At first glance it may seem that our results do not corroborate any of these studies, as we found significant difference only between day 1 and 1 month after discharge, but our results actually do agree with the 2 former studies. Although the change in $\mathrm{P}_{\text {Imax }}$ between admission and discharge in our study was not statistically significant, higher values were observed at discharge: an $11 \%$ increase in $\mathrm{P}_{\text {Imax }}$, in comparison to day 1 , which is $68 \%$ of the whole improvement in $\mathrm{P}_{\text {Imax }}$. One possible explanation to the lack of statistical significance may be the post hoc analysis, which might have been underpowered.

At hospital admission the inspiratory muscle dysfunction was found to be related to the reduction in inspiratory capacity, which supports previous explanations for the reduction in inspiratory muscle strength during exacerbation. Martínez-Llorens et al ${ }^{11}$ and González et al ${ }^{12}$ thought this reduction was due to the mechanical disadvantage caused by hyperinflation: a mechanism better explained in previous studies by O'Donnell and colleagues. ${ }^{26,27}$ Another factor that supports this hypothesis is the rapid improvement in the absence of any specific treatment for the inspiratory muscles. Nevertheless, other factors, such as malnutrition, inflammatory mediators, and corticosteroids, should be investigated, since they might contribute to respiratory muscle dysfunction.

In the present study the inspiratory capacity increased between discharge and 1 month after discharge. This means that a more hyperinflated pattern was observed during hospitalization, corroborating our finding of reduced respiratory muscle strength during hospitalization. Inspiratory capacity at discharge was slightly and not signifi- 


\section{Respiratory Muscle Strength During and After Hospitalization for COPD Exacerbation}

Table 2. Lung Function and Peripheral Muscle Strength During and After Hospitalization for COPD Exacerbation

\begin{tabular}{|c|c|c|c|c|}
\hline & Day 1 & Discharge & $\begin{array}{c}\text { One Month } \\
\text { After Discharge }\end{array}$ & $P$ \\
\hline \multicolumn{5}{|l|}{$\mathrm{FEV}_{1}$} \\
\hline $\mathrm{L}$ & $0.74(0.61-0.86)$ & $0.75(0.61-0.86)$ & $0.69(0.59-0.90)$ & .21 \\
\hline$\%$ of predicted & $26(19-32)$ & $25(19-32)$ & $26(21-35)$ & .75 \\
\hline \multicolumn{5}{|l|}{ FVC } \\
\hline $\mathrm{L}$ & $2.07 \pm 0.80$ & $2.04 \pm 0.68$ & $2.10 \pm 0.84$ & .91 \\
\hline$\%$ of predicted & $50(43-68)$ & $51(41-73)$ & $62(41-76)$ & .78 \\
\hline \multicolumn{5}{|l|}{ Inspiratory capacity } \\
\hline $\mathrm{L}$ & $1.93 \pm 0.60$ & $1.59 \pm 0.44$ & $1.99 \pm 0.54 *$ & .02 \\
\hline$\%$ of predicted & $71(58-85)$ & $54(43-85)$ & $70(58-91)$ & .12 \\
\hline \multicolumn{5}{|c|}{ Quadriceps peak torque } \\
\hline Joules & $79 \pm 34$ & $78 \pm 35$ & $85 \pm 38$ & .10 \\
\hline$\%$ of predicted & $66(45-77)$ & $65(51-77)$ & $72(44-81)$ & .37 \\
\hline Newtons/kg & $4.00 \pm 1.49$ & $3.87 \pm 1.39$ & $4.20 \pm 1.36$ & .34 \\
\hline
\end{tabular}

cantly lower than the inspiratory capacity at admission, and we hypothesized that this might be because our subjects were hospitalized for a short period (4 d [3-5 d]), compared to previous studies (around $10 \mathrm{~d}$ ). 5,6,11 Additionally, no clinical protocol was used to treat subjects, meaning that various treatment regimens were used, so some of our subjects might have been discharged without having their lung function completely recovered.

To the best of our knowledge only 2 studies have prospectively assessed expiratory muscle strength during hospitalization for COPD exacerbation, and their results were divergent. Martínez-Llorens et al $^{11}$ found a significant decrease in expiratory muscle strength between admission and discharge, but Pitta et $\mathrm{al}^{5}$ found no significant differences between 3 assessment days ( 2 during hospitalization and 1 after discharge); however, they found an increasing pattern from hospital admission to after discharge. We observed the same pattern in our study, and the difference was statistically significant. Martínez-Llorens et al ${ }^{11}$ stated that the expiratory muscles are not affected by dynamic hyperinflation. We agree that they may not be directly affected as much as the inspiratory muscles, but, based on previous findings $\mathrm{s}^{28}$ and on our own results, it is reasonable to postulate that these variables might be at least related. We observed a negative correlation between expiratory muscle strength and the degree of air-flow limitation and hyperinflation. It is well known in the literature that during hyperinflation the activity of the expiratory muscles is increased, ${ }^{28,29}$ so we believe that the hyperinflation elicited by the exacerbation may over-recruit the expiratory muscles, which might explain the observed negative correlation between $\mathrm{P}_{\text {Emax }}$ and inspiratory capacity. In fact, patients with history of multiple hospital admissions for
COPD exacerbation have greater expiratory muscle strength than more stable patients. ${ }^{7,8}$

Regarding quadriceps peak torque, we observed no difference between the 3 assessment days, similar to Troosters et al. ${ }^{18}$ Two other studies, ${ }^{5,6}$ however, found a decrease of $5 \%$ of predicted in quadriceps peak torque during the hospitalization period. Besides the study of Troosters et al, ${ }^{18}$ which found no decrease in this variable, Spruit et $\mathrm{al}^{6}$ found that $48 \%$ of their subjects had no change or an increase in quadriceps peak torque. We hypothesize that maybe there is a phenotype of patients more prone to peripheral muscle dysfunction during exacerbation. Furthermore, for quadriceps peak torque, differences in sample characteristics and pharmacologic and physiotherapies used during hospitalization may account, at least in part, for these conflicting results.

Our study clarifies previous findings in the literature, and its main message is possibly that the hyperinflation during the onset of an exacerbation impacts the respiratory muscles, further reducing their strength.

\section{Limitations}

The main limitation of our study is that we did not know the subjects' respiratory muscle strength before hospitalization. However, the inclusion of that assessment moment would logistically complicate the study. Another point of concern is that we used a volitional test, maximum static pressure measured at the mouth, to assess respiratory muscle strength. The test we used, however, is valid, simple to perform, and better tolerated by patients than are nonvolitional tests ${ }^{15}$ that some researchers consider the goldstandard method. More specific assessment of respiratory 


\section{Respiratory Muscle Strength During and After Hospitalization for COPD Exacerbation}

muscle strength, however, could provide new results, although probably not different ones.

We also did not prospectively assess outcomes such as dyspnea, quality of life, or blood gas values, which could provide further understanding of the respiratory muscles' behavior. Those outcomes, however, can also be influenced by others such as hyperinflation or exercise capacity, complicating the analysis of their relationship with the respiratory muscles. In our study, the moments of assessment were not standardized among subjects, which can also be considered a limitation. However, the hospital where the subjects were assessed did not use any standardized protocol for exacerbated COPD patients, which compromises a standardized assessment.

Another point of criticism could be the use of the $t$ test, rather than analysis of variance, for the sample size calculation. However, the direct application of analysis of variance seemed not to be feasible, once different disease severities and time frames were found in the changes we observed.

Finally, the use of peak respiratory pressures instead of one-second plateau pressure or the mean pressure over one second, which are more frequently used, might be another point of concern. However, a very well designed study ${ }^{17}$ concluded that the peak and plateau pressures were comparable in terms of predicted variables, between-subject variability, and reproducibility.

\section{Conclusions}

Patients with COPD exacerbation have inspiratory muscle dysfunction at hospital admission, and inspiratory muscle strength increases markedly by 1 month after discharge. Expiratory muscle strength increases by the time of discharge, and increases more by 1 month after discharge. The degree of air-flow obstruction and hyperinflation at admission are related to both inspiratory and expiratory muscle strength. It is important to investigate the causes of the changes in respiratory muscle strength during COPD exacerbation in future studies, as well as the possible consequences of these changes.

\section{ACKNOWLEDGMENTS}

We thank our hospital staff who helped with subject recruitment and assessment, and we gratefully acknowledge Letícia de Castro and Mônica Yosino Leão Carvalho for their help with data collection.

\section{REFERENCES}

1. Global Initiative for Chronic Obstructive Lung Disease. Global strategy for diagnosis, management, and prevention of COPD (GOLD), revised 2011. http://www.goldcopd.org/uploads/users/files/ GOLD_Report_2011_Feb21.pdf. Accessed September 20, 2013.

2. Soler-Cataluna JJ, Martinez-Garcia MA, Roman SP, Salcedo E, Navarro M, Ochando R. Severe acute exacerbations and mortality in patients with chronic obstructive pulmonary disease. Thorax 2005 60(11):925-931.

3. Miravitlles M, Ferrer M, Pont A, Zalacain R, Alvarez-Sala JL, Masa $\mathrm{F}$, et al. Effect of exacerbations on quality of life in patients with chronic obstructive pulmonary disease: a 2 year follow up study. Thorax 2004;59(5):387-395.

4. Donaldson GC, Seemungal TA, Bhowmik A, Wedzicha JA. Relationship between exacerbation frequency and lung function decline in chronic obstructive pulmonary disease. Thorax 2002;57(10): 847-852.

5. Pitta F, Troosters T, Probst VS, Spruit MA, Decramer M, Gosselink R. Physical activity and hospitalization for exacerbation of COPD. Chest 2006;129(3):536-544

6. Spruit MA, Gosselink R, Troosters T, Kasran A, Gayan-Ramirez G, Bogaerts $\mathrm{P}$, et al. Muscle force during an acute exacerbation in hospitalised patients with COPD and its relationship with CXCL8 and IGF-I. Thorax 2003;58(9):752-756.

7. Vilaró J, Ramirez-Sarmiento A, Martinez-Llorens JM, Mendoza T, Alvarez M, Sanchez-Cayado N, et al. Global muscle dysfunction as a risk factor of readmission to hospital due to COPD exacerbations. Respir Med 2010;104(12):1896-1902.

8. Guerri R, Gayete A, Balcells E, Ramirez-Sarmiento A, Vollmer I, Garcia-Aymerich J, et al. Mass of intercostal muscles associates with risk of multiple exacerbations in COPD. Respir Med 2010;104(3): 378-388.

9. Gonzalez C, Servera E, Ferris G, Blasco ML, Marin J. Risk factors of readmission in acute exacerbation of moderate-to-severe chronic obstructive pulmonary disease. Arch Bronconeumol 2004;40(11): 502-507.

10. Gonzalez C, Servera E, Marin J. Importance of noninvasively measured respiratory muscle overload among the causes of hospital readmission of COPD patients. Chest 2008;133(4):941-947.

11. Martínez-Llorens JM, Orozco-Levi M, Masdeu MJ, Coronell C, Ramirez-Sarmiento A, Sanjuas C, et al. Global muscle dysfunction and exacerbation of COPD: a cohort study. Med Clin (Barc) 2004; 122(14):521-527.

12. González C, Servera E, Celli B, Diaz J, Marin J. A simple noninvasive pressure-time index at the mouth to measure respiratory load during acute exacerbation of COPD: a comparison with normal volunteers. Respir Med 2003;97(4):415-420.

13. Laghi F, Tobin MJ. Disorders of the respiratory muscles. Am J Respir Crit Care Med 2003;168(1):10-48.

14. Rodriguez-Roisin R. Toward a consensus definition for COPD exacerbations. Chest 2000;117(5 Suppl 2):398S-401S.

15. American Thoracic Society; European Respiratory Society. ATS/ ERS Statement on respiratory muscle testing. Am J Respir Crit Care Med 2002;166(4):518-624

16. Black LF, Hyatt RE. Maximal respiratory pressures: normal values and relationship to age and sex. Am Rev Respir Dis 1969;99(5): 696-702.

17. Windisch W, Hennings E, Sorichter S, Hamm H, Criee CP. Peak or plateau maximal inspiratory mouth pressure: which is best? Eur Respir J 2004;23(5):708-713.

18. Troosters T, Probst VS, Crul T, Pitta F, Gayan-Ramirez G, Decramer $\mathrm{M}$, et al. Resistance training prevents deterioration in quadriceps muscle function during acute exacerbations of chronic obstructive pulmonary disease. Am J Respir Crit Care Med 2010;181(10): 1072-1077.

19. Probst VS, Troosters T, Heuzel K, van Bael J, Decramer M, Gosselink R. Comparison of two devices for measuring quadriceps force in COPD patients (abstract). Eur Respir J 2004;24(Suppl 48):666S.

20. Decramer M, Lacquet LM, Fagard R, Rogiers P. Corticosteroids contribute to muscle weakness in chronic airflow obstruction. Am J Respir Crit Care Med 1994;150(1):11-16. 


\section{Respiratory Muscle Strength During and After Hospitalization for COPD Exacerbation}

21. Miller MR, Hankinson J, Brusasco V, Burgos F, Casaburi R, Coates A, et al. Standardisation of spirometry. Eur Respir J 2005; 26(2):319-338.

22. Pereira CA, Sato T, Rodrigues SC. New reference values for forced spirometry in white adults in Brazil. J Bras Pneumol 2007;33(4):397-406.

23. Neder JA, Andreoni S, Castelo-Filho A, Nery LE. Reference values for lung function tests. I. Static volumes. Braz J Med Biol Res 1999;32(6):703-717.

24. Kovelis D, Segretti NO, Probst VS, Lareau SC, Brunetto AF, Pitta F. Validation of the modified pulmonary functional status and dyspnea questionnaire and the Medical Research Council scale for use in Brazilian patients with chronic obstructive pulmonary disease. J Bras Pneumol 2008;34(12):1008-1018.
25. Tantucci C, Donati P, Nicosia F, Bertella E, Redolfi S, De VM, et al. Inspiratory capacity predicts mortality in patients with chronic obstructive pulmonary disease. Respir Med 2008;102(4):613-619.

26. O'Donnell DE, Parker CM. COPD exacerbations. 3: pathophysiology. Thorax 2006;61(4):354-361.

27. O'Donnell DE, Guenette JA, Maltais F, Webb KA. Decline of resting inspiratory capacity in COPD: the impact on breathing pattern, dyspnea, and ventilatory capacity during exercise. Chest 2012;141(3): 753-762.

28. Decramer M. Hyperinflation and respiratory muscle interaction. Eur Respir J 1997;10(4):934-941.

29. O'Donnell DE. Dynamic lung hyperinflation and its clinical implication in COPD. Rev Mal Respir 2008;25(10):1305-1318. 